\title{
Genetic Divergence in Ginger (Zingiber officinale Rosc)
}

\author{
H. Dev* and Vipin Sharma \\ Department of Vegetable Science, Dr YS Parmar University of Horticulture and Forestry, \\ Nauni, Solan 173 230, Himachal Pradesh, India \\ *Corresponding author
}

\section{A B S T R A C T}

\begin{tabular}{l} 
K e y w o r d s \\
$\begin{array}{l}\text { Ginger, Zingiber } \\
\text { officinale, Genetic } \\
\text { divergence, Cluster } \\
\text { analysis, Quality, } \\
\text { yield }\end{array}$ \\
\hline Article Info \\
$\begin{array}{l}\text { Accepted: } \\
\text { 24 July 2020 } \\
\text { Available Online: } \\
\text { 10 August } 2020\end{array}$ \\
\hline
\end{tabular}

Forty ginger genotypes collected from different parts of the country including one recommended variety Himgiri as check were planted, at the Experimental Farm of the Department of Vegetable Science, Dr. YS Parmar University of Horticulture and Forestry, Nauni, Solan (HP) during Kharif season of 2011 and evaluated for different yield and yield contributing traits. The observations were recorded on emergence, number of tillers and leaves per plant, leaf length and breadth, plant girth and height, length, girth, core diameter and weight of mother, primary and secondary rhizomes, number of primary and secondary rhizomes per plant, yield per plant, per plot and per hectare, incidence of rhizome rot, dry matter and oleoresin content. In the present studies, on the basis of genetic divergence, forty diverse genotypes of ginger were grouped into four clusters. This makes the genotypes to be highly divergent and maximum number of genotypes were accommodated in cluster-I. The average intra cluster distance was maximum in cluster-III and minimum in cluster-IV, whereas, maximum inter cluster distance was recorded between cluster-II and III. Cluster-II performed better for majority of traits viz. leaf length, length, core diameter and weight of primary and secondary rhizomes, dry matter recovery and yield per plant with lesser incidence of rhizome rot. Thus, on the basis of cluster means of different characters, effective clonal selection can be made for obtaining superior high yielding varieties in ginger.

\section{Introduction}

Ginger (Zingiber officinale Rosc.) is an important cash crop and one of the principal spice crops all over the country and world belonging to the family Zingiberaceae. Botanically, it is herbaceous perennial, underground modified stem called rhizome and grown as an annual. India is the largest producer and exporter of ginger in the world. It is an important tropical horticultural plant valued all over the world from ancient period for its aroma, flavour and also medicinal properties. Ginger has basic antiseptic properties and is used as a carminative and stimulant. It is also used in veterinary medicine and preparing ayurvedic, homeopathic and allopathic medicines. India, China, Japan, Jamaica, Sierra Leone, Taiwan, Thailand, Nigeria and Australia are the main producers of ginger (Pruthi, 1998). In India, it is grown in an area of 1,60,000 hectares with 
an annual production of $11,18,000$ tonnes during 2017-18 (Anonymous, 2018). In the country, important ginger growing states are Kerala, Odisha, Tamil Nadu, West Bengal and Himachal Pradesh. In Himachal Pradesh, ginger is an important cash crop of mid and low hills, covering an area of 2300 hectares with an annual production of 15,300 tonnes (Anonymous, 2017). In the state it is intensively cultivated in districts like Sirmour, Solan, Bilaspur, Mandi, Hamirpur, Una and Kangra. In all these areas locally adapted material is cultivated, as the seed of the released variety is not available in the required quantity. There is no substitute of this crop in the state and the produce find markets in the adjoining states like Punjab, Uttarakhand, Haryana, Delhi, Uttar Pradesh and Jammu \& Kashmir. It is estimated that more than $90 \%$ of ginger produced in the state is sold fresh in these markets. Ginger is propagated vegetatively as flowers are seldom formed and no seed setting takes place. Because of this nature of the crop it devoid the conventional breeding approach like hybridization, therefore, selection is the easiest method of improving the crop other than mutation and polyploidy breeding. Thus, most of the crop improvement programmes of this species are confined to evaluation and selection of naturally occurring clonal variations. In such species, the extent of genetic diversity is low, unless germplasm is collected from diverse agro-ecological conditions. Therefore, diversity analysis and identification of genetically distant clones or genotypes are central to the ginger improvement programme. Information on genetic diversity can be used to identify the promising diverse genotypes. Considering these aspects and importance of ginger, the present study deals with the genetic divergence of ginger germplasm collected from different parts of the country in order to develop selection criteria for improving rhizome yield potentiality of ginger.

\section{Materials and Methods}

The present investigations were carried out at the Experimental Farm of the Department of Vegetable Science, Dr. YS Parmar University of Horticulture and Forestry, Nauni, Solan (HP) during Kharif season of 2011. Forty diverse genotypes of ginger collected from different parts of the country including one recommended variety Himgiri as check was used for the present investigations. Uniform size of rhizomes were directly sown in the field in the month of April, 2011 at a spacing of $30 \times 20 \mathrm{~cm}$ in raised beds of $3 \times 1 \mathrm{~m}$ size, accommodating 50 plants per plot. Drainage channels were also made between plots. Each collection was sown in a Randomized Block Design with three replications. The standard cultural practices recommended in the Package of Practices for Vegetable Crops, were followed to ensure a healthy crop stand (Anonymous, 2009). Data were recorded from the mean of ten plants tagged randomly from each genotype in each replication on different characters viz. emergence, number of tillers and leaves per plant, leaf length and breadth, plant girth and height, length, girth, core diameter and weight of mother, primary and secondary rhizomes, number of primary and secondary rhizomes per plant, yield per plant, per plot and per hectare, incidence of rhizome rot, dry matter recovery and oleoresin content. The genetic divergence in ginger was estimated by Mahalanobis $\mathrm{D}^{2}$ statistics as suggested by Rao (1952).

\section{Results and Discussion}

The analysis of variance revealed highly significant differences among the genotypes for all the characters studied, indicating the existence of wide genetic divergence among them. On the basis of performance of various traits, all the genotypes were grouped into different clusters. Information on genetic diversity was also used to identify the 
promising diverse genotypes. Genotypes from the same origin were placed in separate clusters, indicating wide genetic diversity among them. This may be due to frequent exchange of germplasm between different geographical regions. On the basis of performance of various traits, the clustering pattern of 40 diverse genotypes of ginger has been presented in table 1 .

All the genotypes were grouped into 4 clusters. The resultant four clusters showed genetic diversity. Similar results were also obtained by Singh et al., (2000), Kizhakkayil and Sasikumar (2010). Aragaw et al., (2011), Parmar (2011) and Sajeev et al., (2011). Maximum number of genotypes were accommodated in cluster-I (13) followed by cluster-II (12), cluster-IV (10) and III (5).

Average inter and intra cluster divergence $\left(\mathrm{D}^{2}\right)$ values are presented in table 2 . The diagonal figures in the table represent the intra cluster distances. The intra cluster distance was maximum in cluster-III (3.632) and minimum in cluster-IV (3.035). Whereas, highest inter cluster distance (6.201) was recorded between cluster-II and III and lowest (3.475) between cluster-I and IV.

The existence of diversity among the genotypes was also assessed to a considerable amount of variation in cluster means for different characters. Cluster-II performed better for majority of traits viz. leaf length, length, core diameter and weight of primary and secondary rhizomes, dry matter recovery and yield per plant with lesser incidence of rhizome rot.

Thus, on the basis of cluster means of these characters, effective clonal selection can be made for getting superior high yielding varieties in ginger. Earlier workers like Singh et al., (2000), Aragaw et al., (2011) and Parmar (2011) have also indicated the significance of genetic divergence for these traits in ginger.

Table.1 Clustering pattern of forty genotypes of ginger on the basis of genetic divergence

\begin{tabular}{|c|c|l|}
\hline Cluster & $\begin{array}{c}\text { Number of } \\
\text { genotypes }\end{array}$ & Genotypes \\
\hline I & 13 & $\begin{array}{l}\text { SG10-01, SG10-02, SG10-03, SG10-04, SG10-05, SG10-06, } \\
\text { SG10-07, SG10-08, SG10-09, SG10-10, SG10-26, SG10-27, } \\
\text { SG10-28 }\end{array}$ \\
\hline II & 12 & $\begin{array}{l}\text { SG10-11, SG10-12, SG10-13, SG10-14, SG10-15, SG10-16, } \\
\text { SG10-17, SG10-31, SG10-32, SG10-33, SG10-34, SG10-35 }\end{array}$ \\
\hline III & 5 & SG10-21, SG10-22, SG10-23, SG10-24, SG10-25 \\
\hline IV & 10 & $\begin{array}{l}\text { SG10-18, SG10-19, SG10-20, SG10-29, SG10-30, SG10-36, } \\
\text { SG10-37, SG10-38, SG10-39, Check Himgiri }\end{array}$ \\
\hline
\end{tabular}

Table.2 Average intra and inter cluster distance $\left(D^{2}\right)$

\begin{tabular}{|c|c|c|c|c|}
\hline Cluster & I & II & III & IV \\
\hline I & $\mathbf{3 . 2 6 5}$ & & & \\
\hline II & 4.128 & $\mathbf{3 . 4 8 5}$ & & \\
\hline III & 3.482 & 6.201 & $\mathbf{3 . 6 3 2}$ & \\
\hline IV & 3.819 & 3.475 & 5.317 & $\mathbf{3 . 0 3 5}$ \\
\hline
\end{tabular}


Table.3 Cluster means for different characters among forty genotypes of ginger

\begin{tabular}{|c|c|c|c|c|c|}
\hline \multirow{2}{*}{$\begin{array}{l}\text { Sr. } \\
\text { No. } \\
\end{array}$} & \multirow[t]{2}{*}{ Characters } & \multicolumn{4}{|c|}{ Clusters } \\
\hline & & I & II & III & IV \\
\hline 1. & Emergence (\%) & 70.73 & 75.52 & 77.21 & 74.22 \\
\hline 2. & Number of tillers per plant & 7.96 & 8.74 & 8.31 & 10.01 \\
\hline 3. & Number of leaves per plant & 92.17 & 99.85 & 93.15 & 115.23 \\
\hline 4. & Leaf length $(\mathrm{cm})$ & 25.01 & 26.17 & 24.91 & 25.71 \\
\hline 5. & Plant girth (cm) & 2.90 & 2.88 & 3.00 & 2.74 \\
\hline 6. & Plant height $(\mathbf{c m})$ & 66.34 & 70.23 & 67.65 & 72.55 \\
\hline 7. & Length of mother rhizome (cm) & 9.11 & 8.94 & 9.47 & 9.65 \\
\hline 8. & Core diameter of mother rhizome $(\mathrm{cm})$ & 2.55 & 2.58 & 2.86 & 2.58 \\
\hline 9. & Weight of mother rhizome (g) & 62.79 & 54.90 & 65.92 & 70.43 \\
\hline 10. & Length of primary rhizome $(\mathrm{cm})$ & 4.37 & 4.61 & 4.59 & 4.57 \\
\hline 11. & Core diameter of primary rhizome $(\mathrm{cm})$ & 2.31 & 2.45 & 2.22 & 2.36 \\
\hline 12. & Weight of primary rhizome (g) & 81.26 & 94.70 & 56.66 & 78.18 \\
\hline 13. & Length of secondary rhizome $(\mathrm{cm})$ & 4.35 & 4.85 & 4.10 & 4.66 \\
\hline 14. & Core diameter of secondary rhizome $(\mathrm{cm})$ & 2.30 & 2.45 & 2.10 & 2.42 \\
\hline 15. & Weight of secondary rhizome (g) & 94.28 & 144.41 & 96.45 & 120.16 \\
\hline 16. & Incidence of rhizome rot (\%) & 11.55 & 11.11 & 15.25 & 10.52 \\
\hline 17. & Dry matter recovery $(\%)$ & 19.33 & 20.94 & 19.60 & 19.27 \\
\hline 18. & Oleoresin content $(\%)$ & 4.09 & 3.80 & 3.78 & 4.05 \\
\hline 19. & Yield per plant (g) & 176.02 & 241.98 & 150.24 & 200.29 \\
\hline
\end{tabular}

The cluster means for various horticultural traits are presented in table 3 . The highest mean was recorded in cluster-III (77.21) for emergence (\%) followed by cluster-II (75.52), cluster-IV (74.22) and cluster-I (70.73). Maximum number of tillers per plant were observed in cluster-IV (10.01) followed by cluster-II (8.74), cluster-III (8.31) and cluster-I (7.96). Maximum number of leaves per plant were recorded in cluster-IV (115.23) followed by cluster-II (99.85), cluster-III (93.15) and cluster-I (92.17), while leaf length $(\mathrm{cm})$ was highest in cluster-II (26.17) followed by cluster-IV (25.71), cluster-I (25.01) and cluster-III (24.91). The average plant girth $(\mathrm{cm})$ was maximum in cluster-III (3.00) followed by cluster-I (2.90), cluster-II (2.88) and clusterIV (2.74). Maximum plant height $(\mathrm{cm})$ was recorded in cluster-IV (72.55) followed by cluster-II (70.23), cluster-III (67.65) and
cluster-I (66.34), while length of mother rhizome $(\mathrm{cm})$ was maximum in cluster-IV (9.65) followed by cluster-III (9.47), clusterI (9.11) and cluster-II (8.94). Maximum core diameter of mother rhizome $(\mathrm{cm})$ was obtained in cluster-III (2.86) followed by cluster-II (2.58), cluster-IV (2.58) and cluster-I (2.55). Highest weight of mother rhizome (g) was recorded in cluster-IV (70.43) followed by cluster-III (65.92), cluster-I (62.79) and cluster-II (54.90). Maximum length of primary rhizome $(\mathrm{cm})$ was observed in cluster-II (4.61) followed by cluster-III (4.59), cluster-IV (4.57) and cluster-I (4.37). The maximum core diameter of primary rhizome $(\mathrm{cm})$ was recorded in cluster-II (2.45) followed by cluster-IV (2.36), Cluster-I (2.31) and cluster-III (2.22). Similarly, weight of primary rhizome $(\mathrm{g})$ was also maximum in cluster-II (94.70) followed by cluster-I 
(81.26), cluster-IV (78.18) and cluster-III (56.66). The average length of secondary rhizome $(\mathrm{cm})$ was maximum in cluster-II (4.85) followed by cluster-IV (4.66), clusterI (4.35) and cluster-III (4.10). The maximum core diameter of secondary rhizome $(\mathrm{cm})$ was recorded in cluster-II (2.45) followed by cluster-IV (2.42), cluster-I (2.30) and cluster-III (2.10). Similarly, weight of secondary rhizome (g) was also maximum in cluster-II (144.41) followed by cluster-IV (120.16), cluster-III (96.45) and cluster-I (94.28). For incidence of rhizome rot (\%) cluster- IV (10.52) exhibited minimum value followed by cluster-II (11.11), cluster-I (11.55) and cluster-III (15.52). Maximum dry matter recovery (\%) was observed in cluster-II (20.94) followed by cluster-III (19.60), cluster-I (19.33) and cluster-IV (19.27). The maximum oleoresin content (\%) was recorded in cluster-I (4.09) followed by cluster-IV (4.05), cluster-II (3.80) and cluster-III (3.78). Maximum yield per plant (g) was observed in cluster-II (241.98) followed by cluster-IV (200.29), cluster-I (176.02) and cluster-III (150.24).

\section{References}

Anonymous. 2009. Package of Practices for Vegetable Crops. Directorate of Extension Education, Dr. YS Parmar University of Horticulture and Forestry, Nauni, Solan. 202p.

Anonymous. 2018. Indian Horticulture

Database. http://www.nhb.gov.in [7:00

PM, 23 ${ }^{\text {rd }}$ May 2019].

Anonymous. 2017. Indian Horticulture
Database. http://www.nhb.gov.in [7:00 PM, 25 ${ }^{\text {th }}$ May 2019].

Aragaw M, Alamerew S, Girma $\mathrm{MH}$ and Tesfaye A. 2011. Variability of ginger (Zingiber officinale Rosc.) accessions for morphological and some quality traits in Ethiopia. International Journal of Agricultural Research 6: 444-57.

Kizhakkayil J and Sasikumar B. 2010. Genetic diversity analysis of ginger (Zingiber officinale Rosc.) germplasm based on RAPD and IISR markers. Sci. Hort. 125: 73-76.

Parmar R. 2011. Molecular characterization of Zingiber officinale Rosc. germplasm in HP using RAPD as molecular markers. MSc Thesis. DrYSPUHF, Nauni, Solan, HP.

Pruthi JS. 1998. Spices and Condiments. $5^{\text {th }}$ edn. National Book Trust, New Delhi. pp. 147-52.

Rao R. 1952. Advanced Statistical Methods in Biometrical Research. John Wiley and Sons Inc., New York. pp. 357-63.

Sajeev S, Roy AR, Langrai B, Pattnayak A, Deka BC. 2011. Genetic diversity analysis in the traditional and improved ginger (Zingiber officinale Rosc.) clones cultivated in North East India. Scientia Horticulture. 128: 18288.

Singh PP, Singh VB, Singh HP, Rajan S. 2000. Genetic diversity in ginger (Zingiber officinale Rosc.) with reference to essential oil content. Journal of Spices and Aromatic Crops 9: 161-64.

\section{How to cite this article:}

Dev, H. and Vipin Sharma. 2020. Genetic Divergence in Ginger (Zingiber officinale Rosc). Int.J.Curr.Microbiol.App.Sci. 9(08): 3072-3076. doi: https://doi.org/10.20546/ijcmas.2020.908.347 